\title{
Promising Antifungal Potential of Engineered Non-ionic Surfactant-Based Vesicles: In Vitro and In Vivo Studies
}

\author{
Amit Verma, ${ }^{1}$ Ankit Jain, ${ }^{1,2}$ Ankita Tiwari, ${ }^{1}$ Shivani Saraf, ${ }^{1}$ Pritish Kumar Panda, ${ }^{1}$ and Sanjay K. Jain ${ }^{1,3}$
}

Received 7 September 2020; accepted 7 December 2020

\begin{abstract}
Fungal keratitis (FK) is a corneal infection caused by different fungal species. It is treated by the topical application of natamycin (NAT). Nevertheless, this approach faces many limitations like toxic effects, frequent dosing, resistance, and patient discomfort. The present research reports the development of trimethyl chitosan (TMC) coated mucoadhesive cationic niosomes by a modified thin-film hydration method. TMC was synthesized using a one-step carbodiimide method and characterized by ${ }^{1} \mathrm{H}-\mathrm{NMR}$ and degree of quaternization $(53.74 \pm 1.06 \%)$. NAT, cholesterol (CHOL), span 60 (Sp60), and dicetyl phosphate (DCP) were used to prepare niosomes which were incubated with TMC to obtain mucoadhesive cationic NAT loaded niosomes (MCNNs). MCNNs showed a spherical shape with $1031.12 \pm$ $14.18 \mathrm{~nm}$ size (PDI below 0.3 ) and $80.23 \pm 5.28 \%$ entrapment efficiency. In vitro drug release studies showed gradual drug release from TMC coated niosomes as compared to the uncoated niosomes. MIC assay and disk diffusion assay revealed promising in vitro antifungal potential of MCNNs similar to the marketed formulation. For investigating in vivo performance, ocular retention and pharmacokinetics, ocular irritation, and ulcer healing studies were performed using the rabbit model. Mucoadhesive property and prolonged local drug release improved the safety and efficacy of NAT, suggesting that the developed niosomes could be an emerging system for effective treatment of fungal keratitis.
\end{abstract}

KEY WORDS: fungal keratitis; ocular drug delivery; niosomes; trimethyl chitosan; natamycin.

\section{INTRODUCTION}

Fungal infection of the eye is considered an important cause of remarkable loss of vision in some regions of the world, especially in Asian countries (1,2). The inflammation of the cornea is referred to as keratitis. Various physical, chemical, and biological factors are responsible for different keratitis. The occurrence of infectious or microbial keratitis is quite high and challenging for physicians because of its fast progression and overlapping symptoms $(3,4)$. Fungal keratitis (keratomycosis) is an infection of the cornea due to different pathogenic fungal species. It mainly affects the corneal epithelium and stroma, while the endothelium and anterior parts of the eye might also get infected in serious conditions. Tropical regions favour the occurrence of fungal keratitis in comparison to the temperate areas. Traditionally, it is sought

\footnotetext{
${ }^{1}$ Pharmaceutics Research Projects Laboratory, Department of Pharmaceutical Sciences, Dr. Hari Singh Gour Central University, Sagar, Madhya Pradesh 470003, India.

${ }^{2}$ Department of Materials Engineering, Indian Institute of Science, Bangalore, Karnataka 560012, India.

${ }^{3}$ To whom correspondence should be addressed. (e-mail: drskjainin@yahoo.com)
}

\section{:ล15}

Published online: 03 January 2021 as a disease of rural regions and is often induced by trauma with vegetative material $(5,6)$. Raising incidence has been accounted for widely used contact lenses; particularly bandage contact lenses, and topical steroids $(7,8)$. Fungal keratitis is one of the major reasons of ocular morbidity. Its frequent misdiagnosis as bacterial keratitis leads to the postponement in its treatment. Moreover, because of the unavailability of safe and effective antifungal therapeutics for clinical use, its treatment persists as a challenge. This disease leads to visual disability, and its treatment is quite unmanageable as compared to other corneal infections (9). Recently, antimicrobial peptides have grabbed substantial attention as effective and broad-spectrum antimicrobials with the efficiency to surmount antibiotic resistance (10). Aspergillus, Candida, and Fusarium are such major fungi species that cause FK (11).

The antifungal drugs used for the treatment of fungal keratitis are mainly categorized as polyenes, triazoles, and echinocandins. Topical antifungal therapy is usually required to treat this type of mycotic infections (12). Natamycin is the drug of choice for keratitis especially induced by the filamentous fungi. NAT is a tetraene polyene considered as the most essential agent in the treatment of fungal keratitis. It binds with ergosterol, which is an important constituent of fungal cell membrane resulting in the inhibition of ergosteroldependent fusion of vacuoles as well as membrane fusion and 
fission. It ultimately leads to the leakage of fungal cell membranes resulting in the death of a fungal organism. NAT is the only topical ophthalmic antifungal agent approved by the USFDA $(13,14)$.

Among all the existing novel formulations, niosomes were selected for the delivery of natamycin via the ocular route. Niosomes depict a resemblance to liposomes as the structure and physical properties are concerned (15-17). These surfactant-based vesicular systems provide a longer duration of action of the drug in ocular tissue and minimize the systemic drainage. The niosomes of varying compositions employed for topical ophthalmic drug delivery have enhanced the activity with reduced side effects (18-20). Niosomal formulation (less than $10 \mu \mathrm{m}$ ) has been depicted to be optimum for ophthalmic delivery, for carrying a remarkable quantity of drug moiety, and also shows resistance for "lacrimal flushing effect" (19,21-24). However, these niosomes could not interact properly with negatively charged mucus covering the ophthalmic tissues via electrostatic interaction because this formulation has a negative surface charge due to the presence of charge inducer moiety as a formulation component. Therefore, modification of their surface charge using cationic polymers was needed to improve their mucoadhesive properties. So, chitosan or its derivative is one of the best-suited polymers for the modification of niosomal surface to improve the delivery of drug in the ocular region. Chitosan is a polycationic polymer and is generally recognized as safe (GRAS) (25). It has bioabsorbable and biodegradable characteristics. Chitosan undergoes interaction with the polyanionic surface of the ocular mucosa, i.e. mucin layer via hydrogen bonding/ionic interactions, and ultimately increases the mucoadhesive potential of formulation $(26,27)$. However, chitosan has many limitations as a polymer for ocular delivery, i.e. irritation, toxicity, and low penetration potential. To overcome these limitations, recently, $N$-trimethyl chitosan (TMC), a positively charged quaternized polyelectrolyte derivative of chitosan, was synthesized to enhance the solubility of chitosan over a broad $\mathrm{pH}$ range (28). It has lower toxicity and higher mucoadhesive property in comparison to chitosan. It also acts as a better absorption enhancer for deep therapy in case of fungal infection due to its ability to cross the tight junction of epithelial cells of the eye surface. Due to the cationic nature of trimethyl chitosan, it can interact with mucus as well as epithelial cells and initiate a redistribution of cytoskeletal F-actin and the tight junction protein ZO-1. This mechanism causes opening of cellular tight junctions and enhancing the paracellular permeability of the epithelial barrier present at the ocular surface, hence alleviating paracellular pathways (29). Even at the neutral $\mathrm{pH}$ (ocular $\mathrm{pH}$ ), TMC retains its cationic charge and shows appreciable solubility in media (30). TMC molecules are adsorbed onto the surface of the niosome, as a film. The positive charge of TMC induces the repulsive forces between vesicles which keeps them in a colloidal state and prevents their fusion, in order to enhance their stability (31-33). It has been accounted that TMC, with an optimum degree of quaternization, is a good absorption enhancer for the paracellular transport of therapeutic moieties (34). TMC-coated niosomes have longer residence time compared to uncoated niosomes due to the mucoadhesive property. Hence, these mucoadhesive TMC coated niosomes improve the ocular bioavailability of therapeutic moiety due to $\mathrm{pH}$-independent drug release and efficient binding with the corneal surface due to surface modification.

The major objective of this research was to synthesize TMC and develop TMC coated natamycin containing niosomes which have mucoadhesive characteristics with cationic charge. The TMC coated and uncoated niosomes were characterized for surface morphology, particle size, zeta potential, and in vitro release. These mucoadhesive niosomes offer greater affinity to the corneal surface in comparison with uncoated drug delivery systems. The use of these mucoadhesive cationic NAT loaded niosomes (MCNNs) as ophthalmic delivery systems was inquired by analysing the in vitro antifungal, pharmacokinetic ( $\mathrm{PK})$, and pharmacodynamic (PD) profile and comparing the observed PK parameters with the marketed formulation. Additionally, the ocular pharmacokinetic profiles and PK/PD indices were also determined as preclinical investigation in the rabbit model. The overall treatment strategy of fungal keratitis is depicted in Fig. 1.

\section{PREPARATION AND CHARACTERIZATION}

\section{Materials and Methods}

\section{Materials}

Natamycin was procured from AKUMS Drugs \& Pharmaceuticals Ltd. (Haridwar, UK, India). Dicetyl phosphate (DCP), chitosan (low molecular weight), triethylamine, iodomethane, and $N$-methylpyrrolidone (NMP) were purchased from Sigma-Aldrich, India. Sterile blank disks, MOPS (3-( $N$-morpholino)propanesulfonic acid) buffer, Sabouraud dextrose agar media, RPMI (Roswell Park Memorial Institute) media, and cholesterol (CHOL) were procured from HiMedia, Mumbai, India. Span 60 (Sp60) and sodium hydroxide were purchased from $\mathrm{CDH}$ (Central Drug House; New Delhi, India). Sodium chloride and acetone were purchased from Fisher Scientific India. Cellulose acetate membrane filter (syringe filter) was purchased from Chromatopak. Methanol and chloroform (Merck Life Science Pvt. Ltd., Mumbai, India), phosphotungstic acid (LobaChemie), sodium hydrogen carbonate, and calcium chloride (CDH, New Delhi) were obtained from the departmental chemical store. The marketed anti-keratitis eye drops, Nataforce (5\% w/v, Mankind), was purchased from Netmeds. Ultrapure water (Millipore, Bedford, MA) was used throughout the studies. All other chemicals were of the highest grade commercially available.

\section{Synthesis of N-Trimethyl Chitosan}

Trimethyl chitosan was synthesized using a slightly modified method reported by Cao et al. (2009) where low molecular weight (LMW) chitosan (2 g) and sodium iodide (4.8 g) were dissolved in 1-methyl-2-pyrrolidinone $(80 \mathrm{~mL})$, and continuously stirred at $60^{\circ} \mathrm{C}$ on a water bath. After the dissolution of chitosan, $15 \%$ aqueous sodium hydroxide 


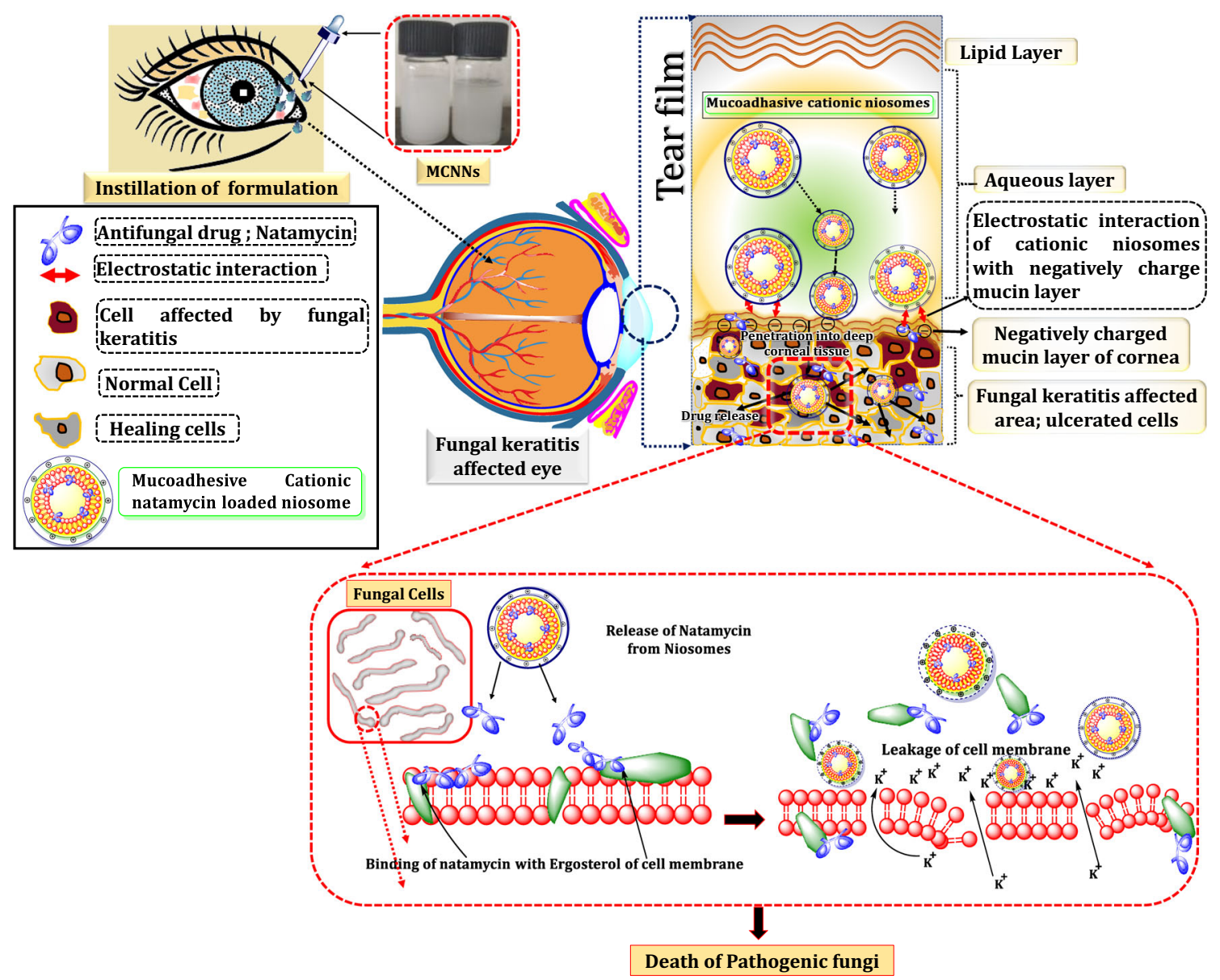

Fig. 1. Diagrammatic representation of treatment of fungal keratitis

solution $(11 \mathrm{~mL})$ and methyl iodide $(11.5 \mathrm{~mL})$ were introduced into the above mixture. It was subjected to continuous stirring for $1 \mathrm{~h}$ (35). The product was precipitated out using ethanol and centrifuged. The separated mass was solubilized in $40 \mathrm{~mL}$ of water and $250 \mathrm{~mL}$ of $1 \mathrm{M} \mathrm{HCl}$ [ethanol $(96 \%)$ ] was added, thereby substituting the iodide ions with chloride ions. The product was centrifuged and washed using ethanol followed by ether which yielded water-soluble white powder. It was dried at $40^{\circ} \mathrm{C}$ in a vacuum dryer (36-38).

\section{Characterization of TMC}

The modified chitosan was characterized by proton nuclear magnetic resonance $\left({ }^{1} \mathrm{H}-\mathrm{NMR}\right)$ spectroscopy. The ${ }^{1} \mathrm{H}-\mathrm{NMR}$ spectrum of the synthesized chitosan was analysed, according to the method proposed by Sieval et al. (1998).

\section{${ }^{1} H-N M R$ Spectroscopy}

Chitosan and trimethyl chitosan were characterized by ${ }^{1} \mathrm{H}-\mathrm{NMR}$ spectroscopy in Sophisticated Analytical Instrumental Facility (SAIF), Panjab University, Chandigarh, India. The synthesized TMC was dissolved in $\mathrm{D}_{2} \mathrm{O}$ and scanned at $400 \mathrm{MHz}$ by an NMR spectrometer (model: Avance II; Bruker, Germany). The ${ }^{1} \mathrm{H}-\mathrm{NMR}$ spectra of chitosan and TMC are shown in Fig. 2a and b, respectively.

\section{Degree of Quaternization}

The degree of quaternization (DQ) is indicated by the number of trimethyl groups present in the structure. The DQ was calculated by ${ }^{1} \mathrm{H}-\mathrm{NMR}$ using Eq. (1):

$\mathrm{DQ}=\left[\frac{\left(\mathrm{CH}_{9}\right)_{9}}{\mathrm{H}} \mathrm{X} \frac{1}{9}\right] \mathrm{X} 100$

where $\left(\mathrm{CH}_{3}\right)_{3}$ is the integral of the peaks corresponding to the nine hydrogen atoms from the trimethylated amino groups at $3.3 \mathrm{ppm}$, and $[\mathrm{H}]$ is the integral of $1 \mathrm{H}$ peaks between 4.7 and $5.7 \mathrm{ppm}$ (reference signals), representing the hydrogen atom bound to the C-1 of the glycopyranose ring of the glucosamine (39).

\section{Formulation and Development of Mucoadhesive Niosomes}

Niosomes were developed by the thin-film hydration technique with few modifications to the previous reported method (40-43). Briefly, definite amounts of NAT (30 mg), Sp60 (66 mg), DCP (5\% w/w), and CHOL (34 mg) were weighed into a $50-\mathrm{mL}$ round-bottom flask (RBF) and dissolved in $10 \mathrm{~mL}$ of chloroform-methanol (3:2, v/v) mixture. The organic phase was removed by evaporation under vacuum at $50^{\circ} \mathrm{C}$ by a rotary evaporator (rotary vacuum evaporator QuickVap, Superfit Rotavapor, India) at $60 \mathrm{rpm}$ 


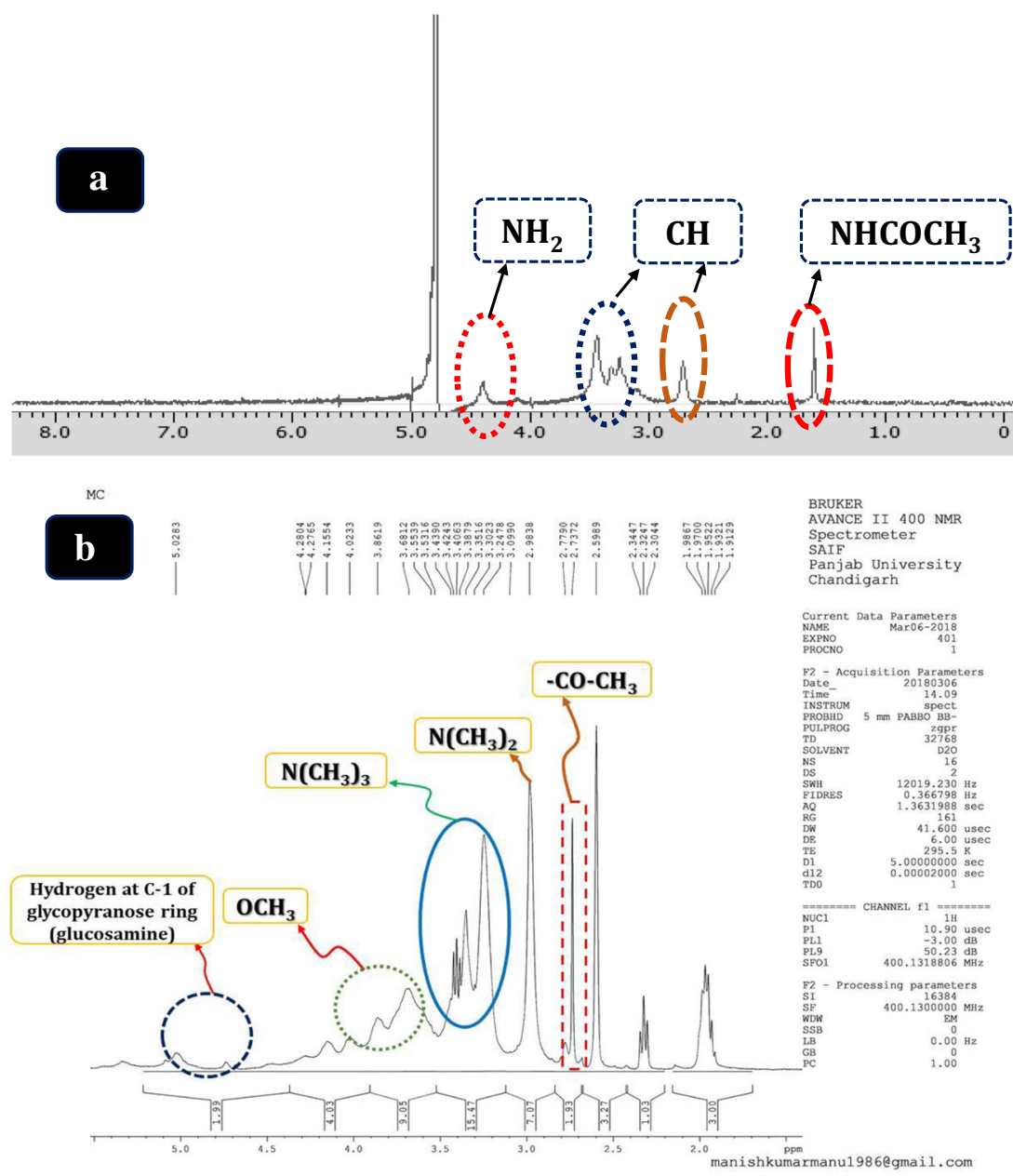

Fig. 2. 1H-NMR spectrum of pure chitosan (a) and synthesized trimethyl chitosan (TMC) (b)

to obtain a thin dry film on the inner wall of the roundbottom flask (44). The dried thin film was then hydrated with phosphate buffer of $\mathrm{pH} 7.4$ [sodium chloride $(8.08 \mathrm{~g})$, disodium hydrogen phosphate $(2.3 \mathrm{~g})$, and potassium dihydrogen phosphate $(0.190 \mathrm{~g})]$ using a rotary evaporator at $50^{\circ} \mathrm{C}$, resulting in the formation of MLVs of niosomes (fig. S1 (a)). The obtained dispersion was sonicated (bath sonicator, Elmasonic S40, Elma, Singen, Germany) for 1 min to yield unilamellar vesicles $(20,36)$.

For the preparation of TMC-coated niosomes, the niosome suspension was added dropwise to equal volumes of TMC solutions $(1 \%$ w/v) under mild magnetic stirring at room temperature (36). After that, the whole mixture was stirred up to $2 \mathrm{~h}$ followed by incubation at $4^{\circ} \mathrm{C}$ for $120 \mathrm{~min}$ (fig. S1 (b)). A two-step ultra-centrifugation process $\left(4^{\circ} \mathrm{C}, 20,000 \times g\right.$, and $\left.1 / 2 \mathrm{~h}\right)$ was used to purify the niosomes resulting in the removal of the unentrapped drug as well as unreacted components. It was washed thrice with phosphate buffer ( $\mathrm{pH} 7.4)$.

\section{Characterization of Niosomes}

\section{Vesicle Size, Size Distribution, and Zeta Potential}

Vesicle size (z-average), size distribution (polydispersity index), and zeta potential (ZP) of prepared niosomes were determined using Nano Plus-3 (version 5.01, Micromeritics Instrument Corporation, Particulate Systems, Norcross, GA, USA) by photon correlation spectroscopy (PCS). Diluted formulation $(1: 9 \mathrm{v} / \mathrm{v})$ was taken into the cuvette and recorded at a $90^{\circ}$ angle. The $\mathrm{ZP}$ of the formulation was computed by the Helmholtz-Smoluchowski equation from their electrophoretic mobility at $20 \mathrm{~V} / \mathrm{cm}$ field strength and $50 \mu \mathrm{s} / \mathrm{cm}$ conductivity (45). The outcomes are shown in fig. 4a to d.

\section{Microscopy}

The morphology and shape of uncoated and TMC-coated niosomal preparations were determined by phase contrast microscopy and transmission electron microscopy (TEM). Both MCNNs and natamycin-loaded uncoated niosomes were mounted on glass slides separately and viewed under a phase contrast microscope (Leica, Germany) and photomicrographs were taken at a suitable magnification. Photographs of uncoated and coated niosomes are shown in fig. $3 \mathrm{e}$ and f. For the TEM study of developed drug delivery systems, a sufficient quantity of both types of niosomes was taken on separate carbon-coated copper grids to form thin films. Phosphotungstic acid (1\%) was used for negative staining (46). The grids were air-dried and observed by TEM (Tecnai, Japan) at suitable magnifications (accelerating voltage of $200 \mathrm{kV}$ ) (Fig. 3g, h). 

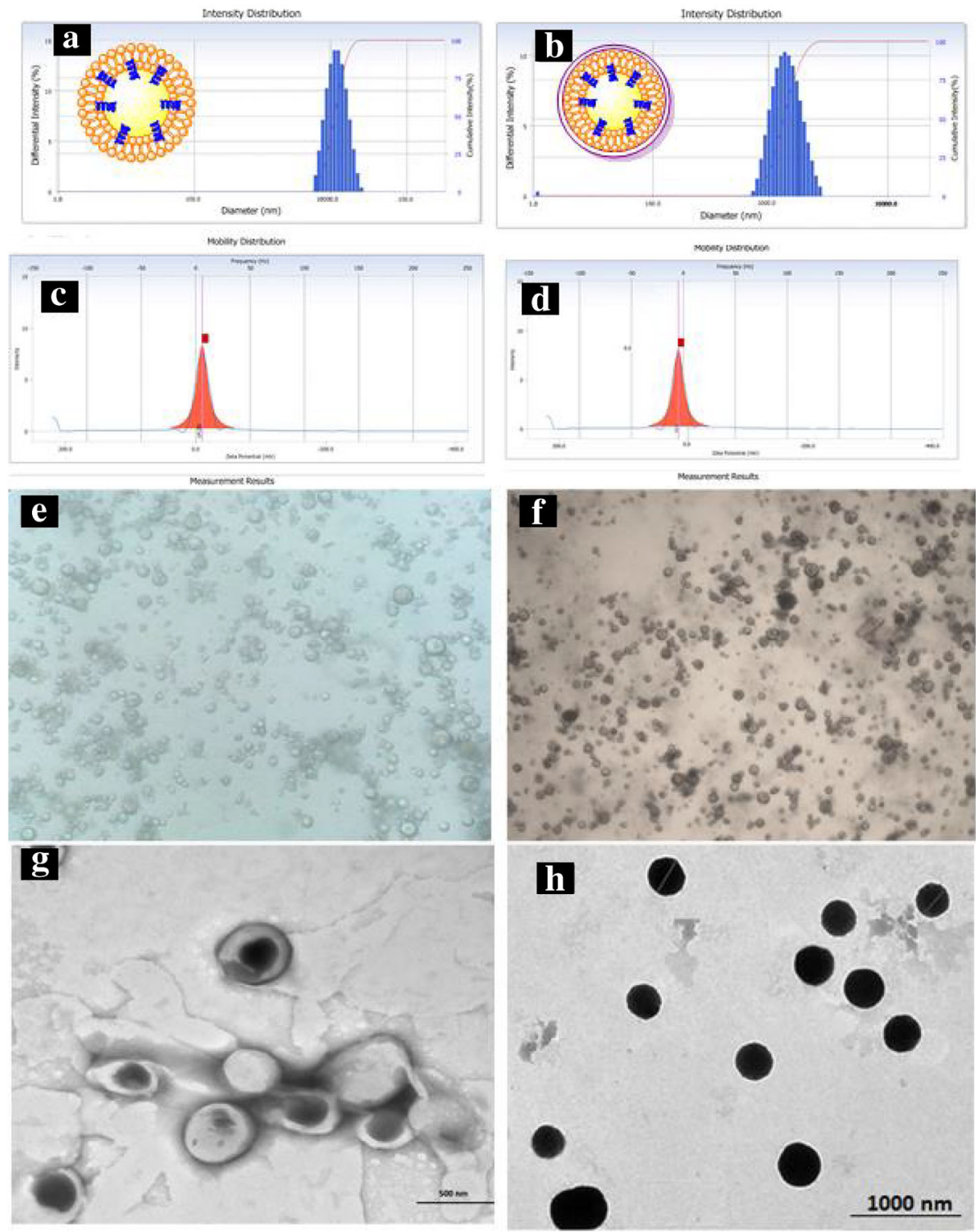

Fig. 3. Size distribution curves $(\mathbf{a}, \mathbf{c})$, zeta potential graphs $(\mathbf{b}, \mathbf{d})$, phase contrast photomicrographs (at $\times 100 ; \mathbf{e}, \mathbf{f})$, and TEM images $(\mathbf{g}, \mathbf{h})$ of NAT loaded uncoated niosomes and MCNNs, respectively

\section{In Vitro Drug Release Study}

In vitro drug release profile was determined using the dialysis bag method (47). PBS ( $\mathrm{pH} \mathrm{7.4)} \mathrm{was} \mathrm{used} \mathrm{for} \mathrm{the}$ determination of drug release from the formulations. MCNNs (equivalent to $30 \mathrm{mg}$ drug) were taken in a dialysis bag (Visking dialysis tubes, 20/30) and it was kept in $100 \mathrm{~mL}$ media $\left(37 \pm 0.5^{\circ} \mathrm{C}\right)$ with stirring at $20-25 \mathrm{rpm}$ (model: Tarsons SPINOT Magnetic Stirrer Hot Plate). Samples were withdrawn from drug release assembly at $2 \mathrm{~h}$ intervals for $24 \mathrm{~h}$ and replaced with PBS ( $\mathrm{pH} 7.4)$ and were dissolved in $100 \mathrm{~mL}$ of distilled water, and $\mathrm{pH}$ was adjusted (7.4 \pm 0.5$)$. Samples were analysed by the HPLC method using Phenomenex Luna C-18 (2) column $(4.6 \times 250 \mathrm{~mm}, \mathrm{dp}=$ $5 \mu \mathrm{m})$ with a mobile phase of methanol:water:acetic acid $(12: 8: 1 \mathrm{v} / \mathrm{v} / \mathrm{v})$, at $303 \mathrm{~nm}$ with a flow rate of $1 \mathrm{~mL} / \mathrm{min}$ [Shimadzu (Kyoto, Japan) HPLC equipment, model-SPDM20A, Hyderabad, India]. The same protocol was repeated with uncoated niosomes $(36,48,49)$. Cumulative \% natamycin release from both formulations was computed from the obtained data and is depicted in fig. 4.

\section{pH Determination}

The $\mathrm{pH}$ values of both types of niosomal systems were assessed using microprocessor-based $\mathrm{pH}$ tester 1 (Eutech Instruments, Oakton) at $25^{\circ} \mathrm{C} \pm 0.5^{\circ} \mathrm{C}$. All measurements were carried out in triplicate.

\section{Percentage Entrapment Efficiency}

The ultra-centrifugation method was used for the measurement of percentage entrapment efficiency (\%EE). The formulation was centrifuged at 20,000 rpm for $60 \mathrm{~min}$ using a cooling centrifuge (Remi Instruments, India) at $4{ }^{\circ} \mathrm{C}$. The vesicles were separated and washed twice with $1 \mathrm{~mL}$ PBS. 


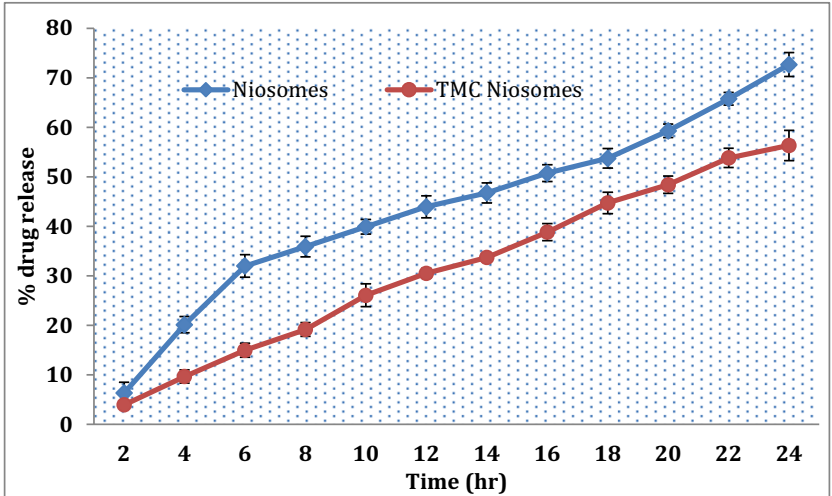

Fig. 4. In vitro drug release from both formulations (uncoated niosomes and MCNNs)

The supernatant was separated each time and assayed using HPLC by Phenomenex Luna C-18 (2) column $(4.6 \times 250 \mathrm{~mm}$, $\mathrm{dp}=5 \mu \mathrm{m})$ with a mobile phase of methanol:water:acetic acid $(12: 8: 1 \mathrm{v} / \mathrm{v} / \mathrm{v})$, at $303 \mathrm{~nm}$ with a flow rate of $1 \mathrm{~mL} / \mathrm{min}$ (Shimadzu (Kyoto, Japan) HPLC equipment, model-SPDM20A, Hyderabad, India) (50). The \%EE was determined by the following formula:

$\% \mathrm{EE}=\frac{(\text { Total amount of drug })-(\text { drug present in supernatant })}{\text { Total amount of drug }} \mathrm{X} 100$

\section{In Vitro Antifungal Activity or Antibiotic Susceptibility Testing}

In vitro susceptibility tests aid in the determination of the potential of a chosen drug that can be used for the treatment of any infectious disease. Susceptibility of fungi isolates to antimicrobial agents is standardized by Clinical Laboratory Standards Institute (CLSI) and regulations are available for disk diffusion (DD) assay (CLSI M02-A10, 2009), minimum inhibitory concentration (MIC) assay (CLSI M07-A8, 2009), and time-kill kinetics assay. The MCNNs, Nataforce (NTF; marketed formulation), and free drug were analysed for antifungal activity by evaluating using Candida albicans (MTCC 183) as a test organism by $\mathrm{MIC}_{90}$, disk diffusion assay, and time-kill kinetics assay (51).

\section{Culture of Candida albicans}

The spores of Candida albicans were purchased from Microbial Type Culture Collection and Gene Bank (MTCC;183), Research Institute, Chandigarh. The spores of Candida albicans were grown on Sabouraud dextrose agar (SDA) for 1-2 days at a temperature of $28-30^{\circ} \mathrm{C}$ and subcultured two times to assure purity and viability. Several agar plugs were then removed from each plate followed by placing them in sterile freezer tubes and frozen at $-70^{\circ} \mathrm{C}$. Individual yeast suspensions were prepared in sterile $0.85 \%$ saline from five or more colonies of each culture $(1 \mathrm{~mm}$ diameter). The yeast cells were dispersed in sterile $0.85 \%$ saline and the turbidity of the sample was measured and adjusted by a Bausch \& Lomb Spectronic 88 spectrophotometer (model Milton Roy Spectronic, Rochester, NY) at $530 \mathrm{~nm}$ to a final transmission which ranged from 75 to
$77 \%$. Inoculum quantitation was done by quantitative colony plate counts of the cell suspensions to receive the actual number of $\mathrm{CFU} / \mathrm{mL}$. The adjusted suspensions were vortexed and diluted (1:100) in distilled water. The diluted suspensions were also vortexed, and about $0.01 \mathrm{~mL}$ aliquots were spread on Sabouraud dextrose agar plates with the help of a calibrated quantitative loop. The plates were incubated at $28-30^{\circ} \mathrm{C}$, and the $\mathrm{CFU} / \mathrm{mL}$ counts were found out after $48 \mathrm{~h}$ $(52,53)$.

\section{Serial Dilution Method for determination of MIC}

The serial dilution method is the most suitable technique for the measurement of MIC. The MIC assay is widely employed to measure the susceptibility of fungi/yeasts to the antifungal agents. The MIC is defined as the "lowest concentration of a drug that will inhibit the visible growth of an organism after incubation". MIC in the case of fungi is also known as minimum fungicidal concentration (MFC), and commonly known as the minimum lethal concentration (MLC). The effect of the drug-loaded niosomes on the antifungal efficacy was measured in terms of $\mathrm{MIC}_{90}$ (54).

The broth microdilution test was performed with sterile, disposable microtitration multi-well plates (96 wells) as per CLSI. The test was performed by serial dilutions of NATloaded niosomal suspensions, NTF (marketed product), and as a free drug (natamycin). Natamycin stock solution $(1000 \mu \mathrm{g} / \mathrm{mL})$ was prepared in an organic solvent (methanol). The drug was diluted in a serial $(2 \times)$ manner and dispensed $(100-\mu \mathrm{L}$ volume) into the wells (rows 1 to 10$)$ of the sterile microtitre plates with a multi-channel pipette. These drug solutions were diluted in a serial manner, i.e. 2.5, 5.0, 10.0, 20.0, 40.0, 80.0, 160.0, 320.0, 640.0, and 1280.0. These drug dilutions were made for microdilution tests and were stored overnight at 4 to $6^{\circ} \mathrm{C}$ before testing.

In the microdilution test, row 1 of the microtitre plate held the highest drug concentration, and row 10 held the lowest drug concentration. The "Blank" present in row 11 contained only plain drug in cell suspension free medium, i.e. RPMI growth medium with l-glutamine and MOPS buffer (pH 7.0). Row 12 was assigned as "control" and the wells of this row contained only sterile drug-free medium with the cell suspensions. This row of the microdilution plate can be employed to perform the sterility control (drug-free medium only). The whole procedure was performed in a laminar flow clean air bench.

For the broth microdilution tests, the cell suspensions were diluted 1:10. Cell suspensions of $C$. albicans were prepared in RPMI 1640 medium and adjusted to give final inoculum concentration of $1.0 \times 10^{3}$ to $5.0 \times 10^{3} \mathrm{CFU} / \mathrm{mL}$. The fungus suspension of $C$. albicans $(100 \mu \mathrm{L})$ was placed in each well, ensuing in the required final concentration and inoculum size. The microplates were incubated at $35^{\circ} \mathrm{C}$ for $24 \mathrm{~h}$. The wells were inoculated on the day of the test with $100 \mu \mathrm{L}$ of adjusted cell suspension. In this way, each tube and/or well contained approximately the same inoculum size per millilitre. Each tube was inoculated with $100 \mu \mathrm{L}$ of adjusted yeast suspension. The final adjusted concentrations in the range of $0.25-128 \mu \mathrm{g} / \mathrm{mL}$ were used. All tubes and plates were incubated at $35^{\circ} \mathrm{C}$, and MIC endpoints were noted at 24 and $48 \mathrm{~h}$. The incubation of microtitre plates was done inside 
Table I. In Vitro Antifungal Susceptibility Testing Using $\mathrm{MIC}_{90}$ and Disk Diffusion Assay

\begin{tabular}{llllll}
\hline Fungal strain & Test substance & MIC $_{90}(\mu \mathrm{g} / \mathrm{mL})$ & \multicolumn{2}{l}{ Zone of inhibition $(\mathrm{mm})$} \\
\cline { 3 - 6 } & & & $10 \mu \mathrm{g}$ & $20 \mu \mathrm{g}$ & $40 \mu \mathrm{g}$ \\
\hline Candida albicans & NTF & 3.64 & $8.62 \pm 0.20$ & $14.25 \pm 0.51$ & $20.18 \pm 1.67$ \\
& MCNNs & 3.59 & $7.91 \pm 0.88$ & $12.54 \pm 0.13$ & $19.76 \pm 1.41$ \\
& Free natamycin & 3.68 & $8.57 \pm 0.45$ & $15.63 \pm 1.16$ & $20.98 \pm 1.01$ \\
\hline
\end{tabular}

$n=3$, average value $\pm \mathrm{SD}$

$M I C_{90}$, minimum inhibitory concentration required to inhibit the growth of $90 \%$ of organisms; NTF, Nataforce; $M C N N s$, mucoadhesive cationic NAT-loaded niosomes

plastic bags to preclude drying. Tubes and wells were noticed for the absence or presence of turbidity (growth). MIC endpoints were scored as recommended by the NCCLS subcommittee. The broth microdilution MIC endpoints were determined with a reading mirror. A comparison of the microbial growth in each drug concentration in tube or well was done with the growth in the control (drug-free) tube or well, and a score was allotted:

- $4+$, no reduction of turbidity or growth;

- $3+$, minor reduction in turbidity;

- $2+$, just half reduction in turbidity;

- $1+$, turbidity with slightly haziness; and

- $\quad 0$, optically clear (no sign of turbidity).

MICs of NAT were defined as the lowest drug concentration in which there was an absence of growth or the observed score was found to be zero (55). The overall schematic representation of the method is shown in fig. S2. The MIC values of all three samples are shown in Table I. Disk Diffusion Assay. A variety of laboratory methods can be used to evaluate or screen the in vitro antifungal activity of any drug substances. Disk diffusion assay is another technique to evaluate the efficacy of antifungal drug-loaded drug delivery systems and antifungal susceptibility of drug for the particular organism. The agarbased DD assay is a substitute way to test the antifungal susceptibility of drug or formulation (56).

SDA was employed as a medium in this estimation. The SDA (6.5 g) was used in distilled water $(100 \mathrm{~mL})$ with constant agitation and heated until boiling for $1 \mathrm{~min}$ to dissolve it completely and the $\mathrm{pH}$ of media was kept at 5.6. The media was sterilized in an autoclave at $121^{\circ} \mathrm{C}$ temperature for $15 \mathrm{~min}$. It was aseptically poured into Petri plates (93$\mathrm{mm}$ diameter) and kept until solidification. The surface of plates was perforated by a sterile cork borer. Candida albicans $\left(0.2 \mathrm{~mL} ; 5 \times 10^{5} \mathrm{CFU} / \mathrm{mL}\right)$ were inoculated onto the agar surface by streaking. The sterile blank disks of MCNNs, NTF, and free drug in DMSO were prepared by pipetting suitable volumes of stock solutions $(10,20$, and $40 \mu \mathrm{g})$ of all three test samples onto the disk. These disks were laid on the solidified agar layer using sterile forceps. Each plate has three disks of different concentrations but these concentrations were similar for all three tests. The plates were incubated at $37^{\circ} \mathrm{C}$ for 1 day. The diameter of the zone of inhibition was measured using an antifungal zone finder and zone of inhibitions were measured (57). Figure 5 and Table I show the different zones of inhibition of MCNNs, NTF, and plain drug natamycin.

\section{Time-Kill Kinetics Assay}

Time-kill kinetics assay is another in vitro susceptibility testing which is conducted with test microorganism species. Measuring the rate of fungicidal activity by time-kill assay can assess the speed by which killing may occur at a given drug concentration (58). Candida strain was selected to assay the time-kill kinetics of developed formulation. C. albicans (MTCC;183) was cultured in Sabouraud dextrose broth and agar. Fungal colonies were incubated overnight for proper
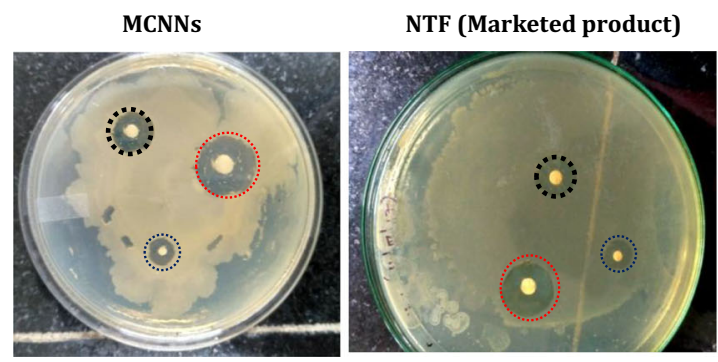

Plain Drug (Natamycin)

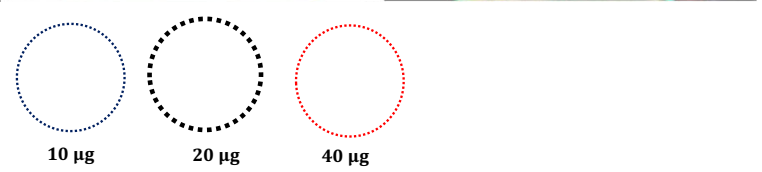

Fig. 5. Sabouraud dextrose agar plates of MCNNs, NTF, and plain drug in different concentrations 
growth. Normal saline was added into it and the fungal cells were adjusted to prepare a standard suspension (59). C. albicans cells in the log growth phase were used to prepare suspensions of $10^{6} \mathrm{CFU} / \mathrm{mL}$ in Sabouraud dextrose broth. A starting inoculum having $10^{6} \mathrm{CFU} / \mathrm{mL}$ was used to measure the time-kill kinetics of the developed formulation. The drug natamycin at the concentrations of $0.5 \times \mathrm{MIC}, 1 \times \mathrm{MIC}, 2 \times$ MIC, and $4 \times$ MIC was added to the cell suspensions. Samples were collected at $0,1,2,4,6,8,10,12,14,16,18,20,22$, and $24 \mathrm{~h}$. The collected samples were plated onto Sabouraud dextrose agar. The numbers of CFU were counted after incubation for $48 \mathrm{~h}$. The broth without natamycin was used as the control for Candida growth at each time point. This method results in a lower limit of detection of $2.0 \log ^{10} \mathrm{CFU} /$ $\mathrm{mL}$ to attain the fungistatic effect. The relationship between the treatment time and the viable cell count $(\mathrm{CFU} / \mathrm{mL})$ was performed by the time-kill curve. Tests were performed in triplicate. All time-kill experiments were done in triplicate (60). The overall time-kill assay is shown in Fig. 6.

\section{In Vivo Characterizations}

To achieve the objective of these studies, a comparison should be done between MCNNs and uncoated niosomes, but results obtained from the uncoated niosomes were not promising. So in vivo studies were performed for the MCNNs and compared with the marketed formulation.

All the animal studies were performed in accordance with the guidelines issued by the Committee for the Purpose of Control and Supervision of Experiments on Animals (CPCSEA), Ministry of Fisheries, Animal Husbandry and Dairying, Department of Animal Husbandry and Dairying, Government of India, which were approved by the Institutional Animal Ethics Committee (IAEC) duly constituted by CPCSEA with approval number 379/CPCSEA/IAEC-2018/ 001 at Department of Pharmaceutical Sciences, Dr. Harisingh Gour University, Sagar (MP), India. The type, species, number of animals, and protocols of studies were approved by the IAEC as per CPCSEA guidelines. The guidelines of CPCSEA comply with the UK Animals (Scientific Procedures) Act, 1986, and associated guidelines, EU Directive 2010/63/EU for animal experiments, or the National Institutes of Health guide for the care and use of laboratory animals (NIH Publication No. 8023, revised 1978). All animal handling guidelines were followed according to the

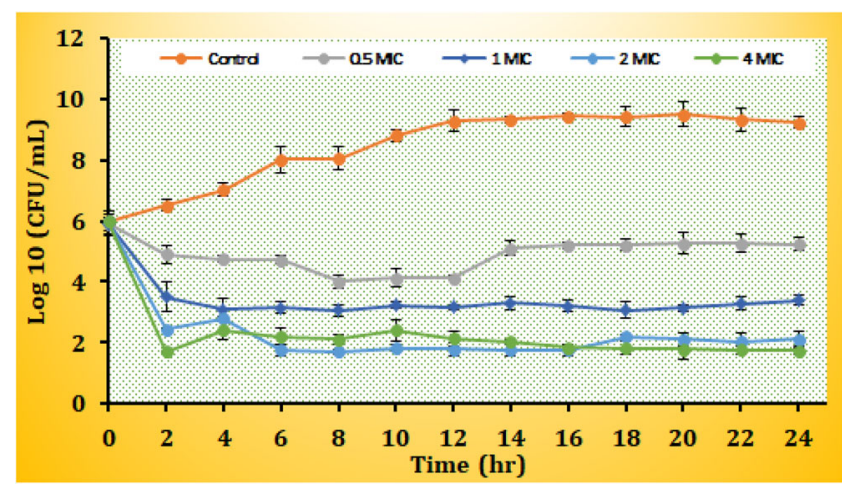

Fig. 6. Time-kill curve of NAT-loaded mucoadhesive cationic niosomes against Candida albicans strain
Association for Research in Vision and Ophthalmology (ARVO) Statement for the Use of Animals in Ophthalmic and Vision Research. Rabbits were provided by the Institutional Animal House, Department of Pharmaceutical Sciences; Dr. Harisingh Gour Vishwavidyalaya, Sagar (MP).

For the in vivo studies, male New Zealand rabbits (3$3.5 \mathrm{~kg}$ ) aged 10 months old were used. Rabbits were placed in an air-conditioned room $\left(22^{\circ} \mathrm{C} \pm 1^{\circ} \mathrm{C}\right)$ with an alternating light-dark cycle and fed a standard pellet diet and water ad libitum (61). During in vivo study, four parameters were evaluated, namely ulcer healing activity, biodistribution, ocular irritation, and ocular retention studies. The pharmacokinetic parameters were obtained from the drug tear profile of treated groups after ocular retention study by the collection of tear fluid. The tear profile was utilized for the measurement of the pharmacokinetic profile of drug for both drug delivery systems. The rabbits were divided into six groups, each group having 6 rabbits (3 groups for MCNNs and the remaining three groups for marketed formulation). The left eye of each rabbit served as control (saline was used instead of formulation) and the right eye was used for the administration of formulations. Both formulations were administered at 12 -h intervals.

\section{Ulcer Healing Activity}

In the ulcer healing study, Candida albicans was cultured on SDA media incubated at $25^{\circ} \mathrm{C}$ for $24 \mathrm{~h}$. $0.5 \mathrm{McF}$ arland standards with the sterile saline solution were used to adjust the turbidity of fungal suspension. Dilute Candida albicans suspension $(5000 \mathrm{CFU} / \mathrm{mL})$ was used for the induction of corneal infection. Experimental rabbits were treated with methylprednisolone injection (100 $\mathrm{mg} / \mathrm{kg})$ intramuscularly (IM) for immunocompromising of animals. The animal was anaesthetised with IM injection of $2 \mathrm{~mL}$ of phenobarbitone sodium $(4 \mathrm{mg} / \mathrm{mL})$. Fungal keratitis was induced by Candida albicans. After that, topical anaesthesia was achieved with proparacaine $\mathrm{HCl}(0.5 \%)$. A corneal incision $(0.1 \mathrm{~mm})$ in the right eye of each rabbit was made with the help of a microsyringe. The fungal suspension $(0.1 \mathrm{~mL})$ was intrastromally injected into the central part of the cornea with the help of a sterile 29-gauge needle.

After $18 \mathrm{~h}$ of inoculation of fungus, corneal oedema, ulceration, dryness, roughness, unevenness, and swelling in eyes of rabbits were observed. After the development of fungal infection, formulations (MCNNs) and marketed preparation (NTF $(5 \% \mathrm{w} / \mathrm{v}))$ were administered topically into the eye of rabbits. In each group that was infected with Candida albicans, the left eyes of rabbits served as control and were treated with sterile saline solution whereas MCNNs and NTF were administered to the right eyes (62). The eyes of each group were examined on days $0,7,14$, and 21 for the status of healing, corner vascularization, iritis, hypopyon, and macular nebula.

Two drops of MCNN formulation were applied topically in the infected area every $12 \mathrm{~h}$, for 21 days. NTF was given in every $2 \mathrm{~h}$ in the first day, followed by every $4 \mathrm{~h}$ for the rest of the days. The eyes of rabbits were observed for various symptoms of fungal keratitis in each day of therapy. The remarkable changes were observed with both formulations during therapy which is shown in Fig. 7. 

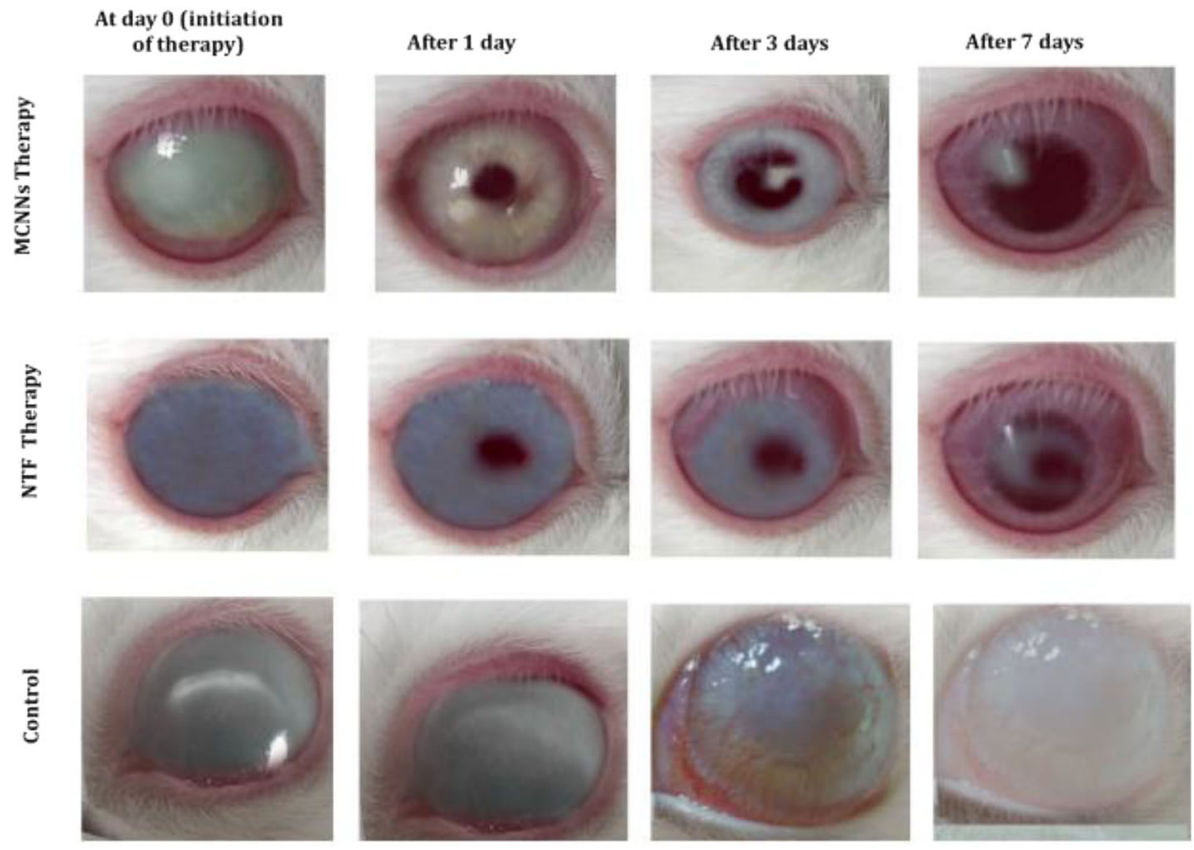

Fig. 7. Changes in ocular surface and healing at different time intervals during therapy

\section{Ocular Irritation Study}

The ocular irritation of MCNNs and NTF was tested by the modified Draize test (63) in the rabbit model. Test formulation $(50 \mu \mathrm{L})$ was applied to the cornea (right eye) every $30 \mathrm{~min}$ for $6 \mathrm{~h}$ (12 treatments). Sterile saline was used as a control. At the end of the therapy, observations were graded into a $0-3$ scale.

The total score for each formulation and controls was calculated. The formulation depicted score more than 5 was nonacceptable for clinical use. The grading of clinical symptoms of fungal keratitis was carried out at 0, 24, 48, 96, and $192 \mathrm{~h}$ after instillation of MCNNs and NTF. Several parameters were observed for irritation potential of formulation, i.e. conjunctiva swelling, redness and discharge, iris hyperemia, and corneal opacity. The index of modified Draize test of MCNNs, NTF, and sterile saline administered to rabbits' eyes is shown in Table II. In Vivo Bioavailability Studies. Both preparations (MCNNs and NTF) were instilled topically as two doses $(50 \mu \mathrm{L}$ each dose) at two different time points $-0 \mathrm{~min}$ and $30 \mathrm{~min}$. Pentobarbital was injected (overdose) into the marginal ear vein of the rabbit $2 \mathrm{~h}$ later from the last administered dose (euthanized). The eyes were washed with ice-cold Dulbecco's phosphate-buffered saline and were immediately enucleated. The ocular tissues such as the cornea, iris-ciliary body (ICB), aqueous humor (AH), and vitreous humor $(\mathrm{VH})$ were separated and stored at $-80^{\circ} \mathrm{C}$. Acetonitrile and $0.1 \%$ formic acid (ice cold) were added to ocular samples to precipitate proteins and extract the drug from the individual tissue, i.e. cornea, $\mathrm{ICB}, \mathrm{AH}$, and $\mathrm{VH}$. The tissue preparations were centrifuged at 13,000 rpm (1 h) and the supernatant was separated. Standard calibration curves generated from different ocular tissues like the cornea (20-500 ng/mL), AH (10-200 ng/mL), VH (10-200 ng/mL), and ICB (10-200 ng/mL) were utilized to estimate the NAT concentration in the samples by using HPLC-UV system. All the standard curves had a coefficient of determination $R^{2} \geq 0.97$. The concentration of NAT from both carrier systems in various ocular tissues is depicted in fig. S3.

\section{In Vivo Ocular Retention Studies and Determination of Pharmacokinetic Parameters as well as PK/PD Indices}

The experimental rabbits were kept in a restraining cage without any restriction in their heads and eye movements. The diet and water intake of rabbits remained normal. Briefly, formulation $(50 \mu \mathrm{L})$ was administered into the lower conjunctival sac by a micropipette. The lacrimal fluid $(10 \mu \mathrm{L})$

Table II. The Index of Modified Draize Test of MCNNs, NTF, and Sterile Saline Solution Applied to Rabbit Eyes $($ Mean \pm SD, $n=3)$

\begin{tabular}{|c|c|c|c|c|c|}
\hline \multirow[t]{2}{*}{ Treatment } & \multicolumn{5}{|c|}{ Clinical scores for conjunctival tissue } \\
\hline & $0 \mathrm{~h}$ & $24 \mathrm{~h}$ & $48 \mathrm{~h}$ & $96 \mathrm{~h}$ & $192 \mathrm{~h}$ \\
\hline Saline & $0.04 \pm 0.01$ & $0.021 \pm 0.0012$ & $0.32 \pm 0.002$ & $0.26 \pm 0.06$ & $0.18 \pm 0.002$ \\
\hline NTF & $2.51 \pm 0.18$ & $2.12 \pm 0.16$ & $1.87 \pm 0.23$ & $1.59 \pm 0.08$ & $1.27 \pm 0.11$ \\
\hline MCNNs & $1.49 \pm 0.03$ & $1.41 \pm 0.026$ & $1.02 \pm 0.42$ & $0.82 \pm 0.18$ & $0.23 \pm 0.09$ \\
\hline
\end{tabular}

$n=3$, average value $\pm \mathrm{SD}$

$N T F$, Nataforce; $M C N N s$, mucoadhesive cationic NAT-loaded niosomes; $S D$, standard deviation 
of the rabbit's eye was withdrawn from the conjunctival sac using calibrated glass capillary at $0,1,2,3,4,5,6,7,8,9,10$, 11 , and $12 \mathrm{~h}$ after the dose. All collected samples were kept in micro-centrifuge tubes at $-20^{\circ} \mathrm{C}$ for the analysis. The quantity of NAT present in lacrimal fluid was assayed by the HPLC method reported previously. This method was best suited for the analysis of samples because it required a small volume. The ocular pharmacokinetics of natamycin which was administered as MCNNs and NTF (5\% w/v) was evaluated for several parameters, i.e. $t_{1 / 2}, C_{\max }, \mathrm{AUC}_{0-12}$, and $\mathrm{MRT}_{0-12}$. The ocular profiles of natamycin from both drug delivery systems in different time intervals are shown in Fig. 8. Different measured pharmacokinetic parameters are depicted in Table III. The relative bioavailability was calculated by using the following equation:

$$
\begin{aligned}
& \text { Relative bioavailability }(\% \mathrm{RB}) \\
& =\frac{\mathrm{AUC}(\mathrm{MCNNs}) \times \text { Dose }(\mathrm{NTF})}{\mathrm{AUC}(\mathrm{NTF}) \times \operatorname{Dose}(\mathrm{MCNNs})} \times 100
\end{aligned}
$$

\section{RESULTS AND DISCUSSION}

\section{Synthesis and Characterization of TMC Polymers}

The structure of TMC polymers was analysed by $1 \mathrm{H}-$ NMR spectroscopy to identify the presence of $N$-trimethyl groups. The spectrum of pure chitosan was shown signals at $4.388,1.601,2.705$, and 3.2 to $3.4 \mathrm{ppm}$ due to the $\mathrm{NH}_{2}$, $\mathrm{NHCOCH}_{3},-\mathrm{CH}-(\mathrm{H} 1)$, and $-\mathrm{CH}-(\mathrm{H} 2, \mathrm{H} 3, \mathrm{H} 4$, and H5) protons, respectively (Fig. 2a). The 1H-NMR spectrum of synthesized TMC was almost similar to the reference spectrum but having some additional peaks which indicates the methylation of chitosan. A $1 \mathrm{H}-\mathrm{NMR}$ spectrum of TMC is depicted in Fig. 2b. The degree of quaternization of the polymer was found to be $53.74 \pm 1.06 \%$ (34). The outcomes also disclosed that the degree of quaternization could be influenced by the number of methylation steps and the base employed in the synthesis (64).

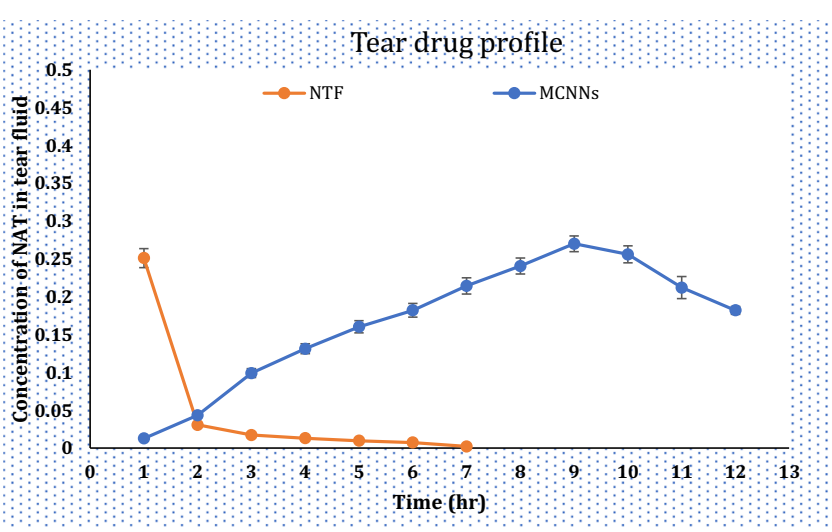

Fig. 8. Tear fluid drug concentration-time profile of NAT in tear fluid of rabbit after topical administration of MCNNs and NTF

\section{Preparation and Characterization of NAT-Loaded Niosomes}

\author{
Vesicle Size, Size Distribution, and Zeta Potential
}

The vesicular size plays an important role in terms of bioavailability and irritation potential. Low-sized $(10 \mu \mathrm{m}$ or less) vesicles retain effectively in cul de sac and also reduced the irritation. The size of the coated and uncoated drug delivery system was found to be $1031.12 \pm 14.18 \mathrm{~nm}$ and $912 \pm$ $10.39 \mathrm{~nm}$, respectively. It was observed that there was an increase in the size of the TMC-coated niosomes due to the coating of chitosan on their surface. The zeta potential for the coated and uncoated formulation was found to be $31.11 \pm$ $1.07 \mathrm{mV}$ and $-14.00 \pm 0.98 \mathrm{mV}$, respectively. The positive zeta potential indicated the coating of TMC onto the surface of niosomes. The vesicle size and zeta potential of both types of niosomal formulations (uncoated and coated niosomes) are depicted in Fig. 3a and $\mathrm{c}$ and $\mathrm{b}$ and d, respectively.

\section{Microscopy}

The shape and morphology of both carriers (uncoated and TMC-coated niosomes) were determined using phase contrast microscopy and it is clearly observed that niosomes are spherical in shape as depicted in Fig. 3e and f. TEM is commonly used to measure the shape, size, and lamellarity of the niosomes. The optimized TEM photomicrographs of niosomal preparations (F2) are illustrated in Fig. 3g and h, which clearly exhibit that these uncoated and coated niosomes are spherical in nanosize that contains a central aqueous core and intact wall (41).

\section{Determination of $\mathrm{pH}$}

The instillation of the formulation to the eye is followed by the stimulation of tear flow and the tear fluids which have the ability to quickly dilute and buffer small volumes of added substances; therefore, the eye can tolerate a wide $\mathrm{pH}$ range. The therapeutic agents used for preparing eye drops should be isohydric and their $\mathrm{pH}$ can deviate from 3.5 to 8.5 , but the range to preclude corneal damage is 6.5 to 8.5 (65). The $\mathrm{pH}$ values of uncoated niosomes and mucoadhesive cationic niosomes were found to be $7.41 \pm 0.04$ and $7.48 \pm 0.09$. So, no observable irritation was shown after the instillation of both formulations. Thus, it has been presumed that the instillation of preparation in the eye should not affect the normal behaviour of tear (66).

\section{Percent Entrapment Efficiency}

During the preparation of natamycin-loaded niosomes, the drug was introduced in the surfactant, DCP, and CHOL mixture. NAT will certainly be entrapped in the lipid bilayer and some hydrophilic part can hang in the aqueous core. This behaviour was expressed due to the amphoteric nature of the drug. The optimum amount of $\operatorname{Sp60}(66 \mathrm{mg})$ and $\mathrm{CHOL}$ $(34 \mathrm{mg})$ provided the maximum entrapment of NAT. The $\% \mathrm{EE}$ analysis was performed by centrifugation method and it was obtained to be $80.23 \pm 5.28 \%$ (36). 
Table III. Different Pharmacokinetic Parameters

\begin{tabular}{|c|c|c|c|}
\hline Parameter (unit) & MCNNs & NTF & $p$ value \\
\hline \multicolumn{4}{|l|}{ Pharmacokinetic parameters } \\
\hline$t_{1 / 2}(\mathrm{~h})$ & $4.065 \pm 0.12$ & $1.5131 \pm 0.075$ & $<0.0001$ \\
\hline$C_{\max }(\mu \mathrm{g} / \mathrm{mL})$ & $0.270 \pm 0105$ & $0.2512 \pm 0.012$ & 0.0005 \\
\hline $\mathrm{AUC}_{0-12}(\mu \mathrm{g} / \mathrm{mL} \times \min )$ & $2.020 \pm 0.091$ & $1.3550 \pm 0.067$ & 0.0042 \\
\hline $\mathrm{MRT}_{0-\infty}(\mathrm{min})$ & $11.292 \pm 0.324$ & $0.413495 \pm 0.010$ & $<0.0001$ \\
\hline AUMC (area under the first moment curve) & $16.741 \pm 0.637$ & $0.56230 \pm 0.012$ & \\
\hline$\% \mathrm{RB}$ & 149.077 & 100 & \\
\hline \multicolumn{4}{|l|}{$\mathrm{PK} / \mathrm{PD}$ indices } \\
\hline$C_{\max } / \mathrm{MIC}$ (unitless) & $0.075 \pm 0.003$ & $0.0690 \pm 0.003$ & $<0.0001$ \\
\hline $\mathrm{AUC} / \mathrm{MIC}(\min )$ & $0.562 \pm 0.028$ & $0.3722 \pm 0.018$ & $<0.0001$ \\
\hline
\end{tabular}

$n=3$, average value $\pm \mathrm{SD}$

$N T F$, Nataforce; $M C N N s$, mucoadhesive cationic NAT-loaded niosomes; $S D$, standard deviation; $A U C$, area under the curve; $A U M C$, area under the first moment curve; $P K / P D$, pharmacokinetic/pharmacodynamic; $M I C$, minimum inhibitory concentration; $M R T$, mean residence time

\section{In Vitro Drug Release Studies}

The structural properties and barrier functions of developed niosomal formulation control the release pattern of NAT. The TMC-coated formulation could serve as a "depot" for sustained release purposes. It could be considered as a novel approach for controlling drug release as well as the removal of burst effect $(30,67,68)$. The cumulative amount $(\%)$ release of NAT from both formulations is depicted in Fig. 4. Anionic niosomes were found to be coated more than neutral niosomes which was because of the strong electrostatic forces. The coated niosomes with the surfactant bilayer and the coating layer alter the drug release. The drug release pattern from both the preparations depicted remarkable differences because of the presence of TMC coating on the surface (69).

\section{In Vitro Antifungal Activity or Antibiotic Susceptibility Testing}

\section{Serial Dilution Method for Determination of MIC}

Minimum inhibitory concentrations (MICs) are utilized to estimate the performance of the remaining methods of susceptibility testing. The effectiveness of an anti-infective agent is determined by the MIC assay. Serial dilution methods are employed to find out the MICs of antimicrobial agents (70). The formulated niosomal suspension was showing a MIC value of $3.59 \mu \mathrm{g} / \mathrm{mL}$. This value was near to the marketed formulation $(3.64 \mu \mathrm{g} / \mathrm{mL})$ and plain drug $(3.68 \mu \mathrm{g} /$ $\mathrm{mL})$. This MIC value of MCNNs depicted that prepared formulation effectively works against the Candida species and demonstrated good antifungal activity. These results revealed that during the development of niosomal formulation, there was no change in the activity of natamycin.

\section{Disk Diffusion Assay}

The disk diffusion studies were performed using the agar diffusion method. The outcomes of disk diffusion revealed that the natamycin-loaded mucoadhesive cationic niosomes importantly suppress the growth of Candida albicans similar to NTF and free natamycin. The outcomes disclosed that the antifungal activity of developed MCNNs was nearly similar to that of marketed ophthalmic suspension as well as a free drug (49). Slight differences were noted which could be due to the formulation having barriers like bilayers and polymer coating. The inhibition zones in all three plates are shown in Fig. 5 and the diameter of zones of inhibition for different formulations is depicted in Table I.

\section{Time-Kill Kinetics Assay}

Initially, natamycin-loaded formulations (MCNNs) with concentrations equivalent to $0.5 \times \mathrm{MIC}, 1 \times \mathrm{MIC}, 2 \times \mathrm{MIC}$, and $4 \times$ MIC were added into the Candida albicans cell-containing tubes. The cells of $C$. albicans in all tubes were present in equal numbers as in control tubes. After the incubation of treated C. albicans, the overall killing effects of NAT with $2 \times \mathrm{MIC}$ and $4 \times$ MIC were more noticeable than the NAT given as $0.5 \times \mathrm{MIC}$ and $1 \times$ MIC. After $2 \mathrm{~h}$, the group treated with the NAT at $0.5 \times$ MIC, $1 \times$ MIC, $2 \times$ MIC, and $4 \times$ MIC showed a dramatic decrease in viable cell count, while the control group showed sharp growth in viable cell count. However, after $24 \mathrm{~h}$ of study, a marked increment in fungal cell number was seen in the $0.5 \times$ MIC-treated groups. And there was no significant change in the number of $C$. albicans cells at $1 \times$ MIC of NAT for $24 \mathrm{~h}$. Thus, it could be concluded that NAT-containing formulations were expressing both time- and concentration-dependent effects on the killing of C. albicans cells (Fig. 6).

\section{In Vivo Characterizations}

\section{In Vivo Ulcer Healing Activity}

The ulcer healing activity was done to assess the effectiveness of MCNNs and NTF in rabbit eyes induced with fungal keratitis. Images during the therapy with NTF $(5 \% w / v)$, MCNNs, and without treatment (control) after 0, 7, 14, and 21 days are depicted in Fig. 7. Sign of fungal keratitis was gradually decreased during therapy with both formulations. The therapy with MCNNs reduced the dosing frequency and increased the effectiveness as compared to the marketed formulation of natamycin. 


\section{Ocular Irritation Study}

The results of in vivo irritation test displayed no sign of irritation or damage in the cornea, conjunctiva, or iris after the topical administering of MCNNs. The scores for MCNN formulation were lower than those of control and marketed formulation. These results supported the potential clinical use of MCNN formulation due to the absence of irritant effects. A modified Draize test was used for the determination of the irritation effect of formulation. Scores of ocular irritation in rabbits treated with MCNNs, NTF, and saline are depicted in Table II.

\section{In Vivo Bioavailability Studies}

Topical application of the dosage forms (MCNNs and marketed NTF solution) in conscious male New Zealand rabbits and NAT levels in all ocular tissues analysed, $2 \mathrm{~h}$ postdosing, were found to be higher with the MCNNs compared to the marketed product (NTF $5 \% \mathrm{w} / \mathrm{v})$. In vivo sample analysis was performed by the HPLC method reported by Balguri et al. (71). The chitosan-modified drug delivery system exhibited mucoadhesive behaviour and showed prolonged retention in ocular tissue. The MCNNs were slightly penetrated into the inner tissue up to the ICB. But, the amount of NTF reaching $\mathrm{VH}$ was non-significant $(p \geq$ $0.05)$. The surfaces of prepared niosomes were coated with the TMC. This TMC helped in the deep penetration into the cornea. The outcomes were in accordance with the in vitro studies. The concentration of NTF was much higher in the cornea compared to the other ocular tissues. The amount of NAT in the cornea $(4.4 \pm 0.21 \mu \mathrm{g} / \mathrm{mL})$ was higher in comparison to other tissues, including the $\mathrm{AH}(2.9 \mu \mathrm{g} / \mathrm{mL})$. These results are in agreement with those obtained in the ex vivo corneal permeation study (36). The concentration of MCNNs and marketed NTF solutions in different regions is depicted in fig. S3. These results demonstrate that MCNNs remained to be retained in the first structures of the eye and released the drug slowly to inner tissues, such as the AH.

\section{In Vivo Ocular Retention Studies and Determination of Pharmacokinetic Parameters as well as PK/PD Indices}

The pharmacokinetic profile of MCNN formulation was determined for the assessment of efficacy in terms of concentration and retention of formulation at the target site (cornea). The different pharmacokinetic parameters were measured by the ocular tear profile from the treated rabbits. The various pharmacokinetic parameters are expressed in Table III.

The ocular pharmacokinetics of NAT administered as MCNNs $(50 \mu \mathrm{L})$ was compared with marketed suspension (NTF; $5 \%$, w/v) when instilled in the eyes of New Zealand white rabbits. The strengths of both carrier systems differed in order to assess the efficiency of MCNNs but the dose remained the same. The drug delivery system maintained the $C_{\max }$ and decreased the nasolacrimal clearance of NAT. The MCNNs increased the $\mathrm{AUC}_{(0-12)}$ up to 1.5-fold. MRT (mean residence time) of MCNNs is more than about 27 times higher than NTF. The positively charged MCNNs bind with the ocular surface by electrostatic interaction. The high ocular bioavailability of NAT from MCNNs, higher $C_{\max }$, and longer half-life were due to the better retention potential of developed drug delivery systems. Bioadhesion of TMCcoated niosomes is not only due to the positive charge of the modified chitosan but could also be potentiated by the presence of free functional groups such as $\mathrm{NH}_{2}$ and $\mathrm{OH}$ onto the surface of polymer which was involved in the formation of hydrogen and other bonding with mucin layer of the eye.

\section{$P K-P D$ Indices}

The estimated PK-PD indices of MCNNs and NTF (5\% $\mathrm{w} / \mathrm{v}$ ) after a single dose in the eyes of New Zealand white rabbits were measured. $C_{\max } / \mathrm{MIC}$ and AUC/MIC were determined. All these indices are shown in Table III. The concentration above the MIC for a long period of time (for 3 life cycles) is better than high concentration for a short duration for the treatment of fungal disease. The pharmacokinetics and in vitro MIC estimation were measured as PK$\mathrm{PD}$ indices in order to predict the antifungal activity. $C_{\max } /$ MIC and AUC/MIC of MCNNs were found to be $0.0752 \pm$ 0.0037 and $0.5626 \pm 0.0281 \mathrm{~min}$, respectively, demonstrating optimum therapeutic activity at a single dose. The $C_{\max } / \mathrm{MIC}$ of MCNNs was higher than that of the NTF. The dose of natamycin was decreased, when the NAT was given in the form of MCNN drug delivery system. Only $2 \%(\mathrm{w} / \mathrm{v})$ dose of natamycin as MCNNs was sufficient for getting optimum efficacy in addition to the reduction of toxicity at the nasolacrimal site. The ocular concentration-time profile curves for both drug delivery systems were obtained and the data were fitted for the best pharmacokinetic model. The computed PK parameters suggested that natamycin should be given as NTF (5\% w/v) in every $120 \mathrm{~min}(2 \mathrm{~h})$ and MCNNs $(2 \% \mathrm{w} / \mathrm{v})$ for every $360 \mathrm{~min}(6 \mathrm{~h})$. The concentration-time simulation duration shows two instillations of MCNNs as compared to 6-times application of NTF suspension in a 12-h period (Fig. 8) for the effective treatment of fungal keratitis. Thus, MCNNs significantly reduced the dose size as well as the dosing frequency of natamycin. The PK-PD indices indicated that the dosage regimen of MCNNs was sufficient to maintain the level of drug above the MIC for a longer duration to get better effectiveness of the drug delivery system with improved patient compliance.

\section{CONCLUSION}

In the present study, TMC-coated natamycin-loaded niosomes aresuperior in pharmaceutical performance to deliver natamycin at the ocular site since TMC coating increased precorneal retention and ocular bioavailability, and prolonged the drug release. When ocular drug delivery systems provide these properties, the dose and frequency of dosing of therapeutic agents can be decreased. The positively charged niosomal vesicles showed improved \% entrapment efficiency and better charge-dependent mucoadhesive properties. The size of the developed formulation was optimal for the successful ocular drug delivery without any irritation at the eye site. The $\mathrm{pH}$ of MCCNs is compatible with the ocular tissue, so less chance of ocular tissue irritation. The niosomal formulation depicted no sign of damage in various ocular tissues like the cornea, conjunctiva, or iris. The ocular 
pharmacokinetic study of NAT helped in the selection of dose and dosage regimen. The niosomal drug delivery offers the potential platform for ocular drug delivery. The niosomal preparation displayed various advantages such as sustained drug release, ease of administration, reduced dosing frequency, and better patient compliance. These data supported the efficacy of niosomes in ocular delivery but further studies are still needed to warrant its clinical efficacy.

\section{ACKNOWLEDGEMENTS}

We are thankful to AKUMS Drugs \& Pharmaceuticals Ltd. (Haridwar, UK, India) for providing the gift sample of natamycin. We are also thankful to PURSE phase II of DST and SIC of Dr Harisingh Gour University, Sagar MP India for providing the instrumentation facility.

\section{COMPLIANCE WITH ETHICAL STANDARDS}

Conflict of Interest The authors declare that they have no conflict of interest.

\section{SUPPLEMENTARY INFORMATION}

The online version contains supplementary material available at https://doi.org/10.1208/s12249-020-01900-z.

\section{REFERENCES}

1. Tuli SS. Fungal keratitis. Clin Ophthalmol. 2011;5:275-9.

2. Garg P, Roy A, Roy S. Update on fungal keratitis. Curr Opin Ophthalmol. 2016;27(4):333-9.

3. Słowik M, Biernat MM, Urbaniak-Kujda D, Kapelko-Słowik K, Misiuk-Hojło M. Mycotic infections of the eye. Adv Clin Exp Med. 2015;24(6):1113-7.

4. Keenan JD, McLeod SD. Fungal keratitis. Ophthalmology EBook. 2018;226.

5. Gopinathan U, Sharma S, Garg P, Rao GN. Review of epidemiological features, microbiological diagnosis and treatment outcome of microbial keratitis: experience of over a decade. Indian J Ophthalmol. 2009;57(4):273-9.

6. Prajna VN, Prajna L, Muthiah S. Reply to comment on: Fungal keratitis: the Aravind experience. Indian J Ophthalmol. 2018;66(2):346-7.

7. Iyer SA, Tuli SS, Wagoner RC. Fungal keratitis: emerging trends and treatment outcomes. Eye Contact Lens. 2006:32(6):267-71.

8. Gower EW, Keay LJ, Oechsler RA, Iovieno A, Alfonso EC, Jones DB, et al. Trends in fungal keratitis in the United States, 2001 to 2007. Ophthalmology. 2010;117(12):2263-7.

9. Mellado F, Rojas T, Cumsille C. Fungal keratitis: review of diagnosis and treatment. Arq Bras Oftalmol. 2013;76(1):52-6.

10. Wu H, Ong ZY, Liu S, Li Y, Wiradharma N, Yang YY, et al. Synthetic $\beta$-sheet forming peptide amphiphiles for treatment of fungal keratitis. Biomaterials. 2015;43:44-9.

11. Nielsen SE, Nielsen E, Julian HO, Lindegaard J, Højgaard K, Ivarsen A, et al. Incidence and clinical characteristics of fungal keratitis in a Danish population from 2000 to 2013. Acta Ophthalmol. 2015;93(1):54-8.

12. Austin A, Lietman T, Rose-Nussbaumer J. Update on the management of infectious keratitis. Ophthalmology. 2017;124(11):1678-89.

13. Arora R, Gupta D, Goyal J, Kaur R. Voriconazole versus natamycin as primary treatment in fungal corneal ulcers. Clin Exp Ophthalmol. 2011;39(5):434-40.
14. Sun CQ, Lalitha P, Prajna NV, Karpagam R, Geetha M, O'Brien $\mathrm{KS}$, et al. Association between in vitro susceptibility to natamycin and voriconazole and clinical outcomes in fungal keratitis. Ophthalmology. 2014;121(8):1495-500.e1.

15. Kaur IP, Garg A, Singla AK, Aggarwal D. Vesicular systems in ocular drug delivery: an overview. Int J Pharm. 2004;269(1):114.

16. Paecharoenchai O, Niyomtham N, Leksantikul L, Ngawhirunpat T, Rojanarata T, Yingyongnarongkul BE, et al. Nonionic surfactant vesicles composed of novel sperminederivative cationic lipids as an effective gene carrier in vitro. AAPS PharmSciTech. 2014;15(3):722-30.

17. Jain A, Jain SK. Chapter 9 - Application potential of engineered liposomes in tumor targeting A2 - Grumezescu, Alexandru Mihai. Multifunctional systems for combined delivery, biosensing and diagnostics: Elsevier; 2017. p. 171-91.

18. Abdelbary G, El-Gendy N. Niosome-encapsulated gentamicin for ophthalmic controlled delivery. AAPS PharmSciTech. 2008;9(3):740-7.

19. Abdelkader H, Wu Z, Al-Kassas R, Alany RG. Niosomes and discomes for ocular delivery of naltrexone hydrochloride: morphological, rheological, spreading properties and photoprotective effects. Int J Pharm. 2012;433(1-2):142-8.

20. Bishnoi M, Jain A, Singla Y, Shrivastava B. Sublingual delivery of chondroitin sulfate conjugated tapentadol loaded nanovesicles for the treatment of osteoarthritis. J Liposome Res. 2020;2:1-15.

21. Uchegbu IF, Vyas SP. Non-ionic surfactant based vesicles (niosomes) in drug delivery. Int J Pharm. 1998;172(1-2):33-70.

22. Sahoo RK, Biswas N, Guha A, Sahoo N, Kuotsu K. Nonionic surfactant vesicles in ocular delivery: innovative approaches and perspectives. Biomed Res Int. 2014;2014:263604.

23. Jain A, Kumari R, Tiwari A, Verma A, Tripathi A, Shrivastava A, et al. Nanocarrier based advances in drug delivery to tumor: an overview. Curr Drug Targets. 2018;19(13):1498-518.

24. Khatol P, Saraf S, Jain A. Peroxisome proliferated activated receptors (PPARs): opportunities and challenges for ocular therapy. Crit Rev Ther Drug Carrier Syst. 2018;35(1):65-97.

25. Jain A, Jain SK. Environmentally responsive chitosan-based nanocarriers (CBNs). Handb Polym Pharm Technol Biodegrad Polym. 2015;3:105.

26. Wadhwa S, Paliwal R, Paliwal SR, Vyas SP. Chitosan and its role in ocular therapeutics. Mini-Rev Med Chem. 2009;9(14):163947.

27. Prajapati SK, Jain A, Jain A, Jain S. Biodegradable polymers and constructs: a novel approach in drug delivery. Eur Polym J. 2019;120:109191.

28. De Britto D, Frederico FR, Garrido Assis OB. Optimization of N, N, N-trimethylchitosan synthesis by factorial design. Polym Int. 2011;60(6):910-5.

29. Choi C, Nam J-P, Nah J-W. Application of chitosan and chitosan derivatives as biomaterials. J Ind Eng Chem. 2016;33:1-10.

30. Moghassemi S, Parnian E, Hakamivala A, Darzianiazizi M, Vardanjani MM, Kashanian S, et al. Uptake and transport of insulin across intestinal membrane model using trimethyl chitosan coated insulin niosomes. Mater Sci Eng C. 2015;46:333-40.

31. Zhang J, Wang S. Topical use of coenzyme Q10-loaded liposomes coated with trimethyl chitosan: tolerance, precorneal retention and anti-cataract effect. Int J Pharm. 2009;372(12):66-75.

32. Van der Merwe S, Verhoef J, Verheijden J, Kotzé A, Junginger H. Trimethylated chitosan as polymeric absorption enhancer for improved peroral delivery of peptide drugs. Eur J Pharm Biopharm. 2004;58(2):225-35.

33. Shinde UA, Joshi PN, Jain DD, Singh K. Preparation and evaluation of N-trimethyl chitosan nanoparticles of flurbiprofen for ocular delivery. Curr Eye Res. 2019 (just-accepted).

34. Thanou M, Florea BI, Langemeyer MW, Verhoef JC, Junginger HE. N-Trimethylated chitosan chloride (TMC) improves the intestinal permeation of the peptide drug buserelin in vitro (Caco-2 cells) and in vivo (rats). Pharm Res. 2000;17(1):27-31.

35. Le Dung P, Milas M, Rinaudo M, Desbrières J. Water soluble derivatives obtained by controlled chemical modifications of chitosan. Carbohydr Polym. 1994;24(3):209-14. 
36. Verma A, Sharma G, Jain A, Tiwari A, Saraf S, Panda PK, et al. Systematic optimization of cationic surface engineered mucoadhesive vesicles employing Design of Experiment (DoE): a preclinical investigation. Int J Biol Macromol. 2019;133:1142-55.

37. Boonyo W, Junginger HE, Waranuch N, Polnok A, Pitaksuteepong T. Preparation and characterization of particles from chitosan with different molecular weights and their trimethyl chitosan derivatives for nasal immunization. J Met Mater Miner. 2017;18(2).

38. Cao J, Sun J, Wang X, Li X, Deng Y. N-Trimethyl chitosancoated multivesicular liposomes for oxymatrine oral delivery. Drug Dev Ind Pharm. 2009;35(11):1339-47.

39. Sayin B, Somavarapu S, Li XW, Sesardic D, Senel S, Alpar OH. TMC-MCC (N-trimethyl chitosan-mono-N-carboxymethyl chitosan) nanocomplexes for mucosal delivery of vaccines. Eur $\mathbf{J}$ Pharm Sci. 2009;38(4):362-9.

40. Obeid MA, Gebril AM, Tate RJ, Mullen AB, Ferro VA. Comparison of the physical characteristics of monodisperse non-ionic surfactant vesicles (NISV) prepared using different manufacturing methods. Int J Pharm. 2017;521(1-2):54-60.

41. Baillie A, Florence A, Hume L, Muirhead G, Rogerson A. The preparation and properties of niosomes-non-ionic surfactant vesicles. J Pharm Pharmacol. 1985;37(12):863-8.

42. Azmin M, Florence A, Handjani-Vila R, Stuart J, Vanlerberghe G, Whittaker J. The effect of non-ionic surfactant vesicle (niosome) entrapment on the absorption and distribution of methotrexate in mice. J Pharm Pharmacol. 1985;37(4):237-42.

43. Udupa N, Chandraprakash K, Umadevi P, Pillai G. Formulation and evaluation of methotrexate niosomes. Drug Dev Ind Pharm. 1993;19(11):1331-42.

44. Al-Mahallawi AM, Khowessah OM, Shoukri RA. Nanotransfersomal ciprofloxacin loaded vesicles for non-invasive trans-tympanic ototopical delivery: in-vitro optimization, exvivo permeation studies, and in-vivo assessment. Int J Pharm. 2014;472(1-2):304-14.

45. Khalil RM, Abdelbary GA, Basha M, Awad GEA, El-Hashemy HA. Enhancement of lomefloxacin Hcl ocular efficacy via niosomal encapsulation: in vitro characterization and in vivo evaluation. J Liposome Res. 2017;27(4):312-23.

46. Gao Y, Elder S. TEM study of TiO2 nanocrystals with different particle size and shape. Mater Lett. 2000;44(3-4):228-32.

47. Muzzalupo R, Tavano L, La Mesa C. Alkyl glucopyranosidebased niosomes containing methotrexate for pharmaceutical applications: evaluation of physico-chemical and biological properties. Int J Pharm. 2013;458(1):224-9.

48. Thangabalan B, Kumar PV. Analytical method development and validation of natamycin in eye drop by RP-HPLC. Asian J Pharm Clin Res. 2013;6(1):134-5.

49. Bhatta RS, Chandasana H, Chhonker YS, Rathi C, Kumar D, Mitra K, et al. Mucoadhesive nanoparticles for prolonged ocular delivery of natamycin: in vitro and pharmacokinetics studies. Int J Pharm. 2012;432(1-2):105-12.

50. El-Badry M, Fetih G, Fathalla D, Shakeel F. Transdermal delivery of meloxicam using niosomal hydrogels: in vitro and pharmacodynamic evaluation. Pharm Dev Technol. 2015;20(7):820-6.

51. Xie L, Zhai H, Zhao J, Sun S, Shi W, Dong X. Antifungal susceptibility for common pathogens of fungal keratitis in Shandong Province, China. Am J Ophthalmol. 2008;146(2):260-5.

52. Pfaller MA, Burmeister L, Bartlett MS, Rinaldi MG. Multicenter evaluation of four methods of yeast inoculum preparation. J Clin Microbiol. 1988;26(8):1437-41.

53. Odds F. Laboratory tests for the activity of imidazole and triazole antifungal agents in vitro. Semin Dermatol. 1985;4:26079.

54. Zhao X, Tong Y, Wang X, Zhang X, Chen S, Lu H. Comparison of the ocular penetration and pharmacokinetics between natamycin and voriconazole after topical instillation in rabbits. J Ocul Pharmacol Ther. 2018;34(6):460-7.

55. Patil A, Lakhani P, Majumdar S. Current perspectives on natamycin in ocular fungal infections. J Drug Deliv Sci Technol. 2017;41:206-12.

56. Kreger BE, Craven DE, McCabe WR. Gram-negative bacteremia. IV. Re-evaluation of clinical features and treatment in 612 patients. Am J Med. 1980;68(3):344-55.

57. Malhotra S, Khare A, Grover K, Singh I, Pawar P. Design and evaluation of voriconazole eye drops for the treatment of fungal keratitis. J Pharm (Cairo). 2014;2014:490595.

58. Nielsen EI, Viberg A, Lowdin E, Cars O, Karlsson MO, Sandstrom M. Semimechanistic pharmacokinetic/ pharmacodynamic model for assessment of activity of antibacterial agents from time-kill curve experiments. Antimicrob Agents Chemother. 2007;51(1):128-36.

59. Klepser ME, Ernst EJ, Lewis RE, Ernst ME, Pfaller MA. Influence of test conditions on antifungal time-kill curve results: proposal for standardized methods. Antimicrob Agents Chemother. 1998;42(5):1207-12.

60. Tsuji BT, Yang JC, Forrest A, Kelchlin PA, Smith PF. In vitro pharmacodynamics of novel rifamycin ABI-0043 against Staphylococcus aureus. J Antimicrob Chemother. 2008;62(1):156-60.

61. Chandasana H, Prasad YD, Chhonker YS, Chaitanya TK, Mishra NN, Mitra K, et al. Corneal targeted nanoparticles for sustained natamycin delivery and their PK/PD indices: an approach to reduce dose and dosing frequency. Int $\mathrm{J}$ Pharm. 2014;477(1-2):317-25.

62. Bhosale R, Bhandwalkar O, Duduskar A, Jadhav R, Pawar P. Water soluble chitosan mediated voriconazole microemulsion as sustained carrier for ophthalmic application: in vitro/ex vivo/in vivo evaluations. Open Pharm Sci J. 2016;3(1).

63. Wilhelmus KR. The Draize eye test. Surv Ophthalmol. 2001;45(6):493-515.

64. Hamman JH, Stander M, Kotze AF. Effect of the degree of quaternisation of $\mathrm{N}$-trimethyl chitosan chloride on absorption enhancement: in vivo evaluation in rat nasal epithelia. Int $\mathrm{J}$ Pharm. 2002;232(1-2):235-42.

65. Gonnering R, Edelhauser HF, Van Horn DL, Durant W. The $\mathrm{pH}$ tolerance of rabbit and human corneal endothelium. Invest Ophthalmol Vis Sci. 1979;18(4):373-90.

66. Üstündağ-Okur N, Gökçe EH, Bozbıyık DI, Eğrilmez S, Özer Ö, Ertan G. Preparation and in vitro-in vivo evaluation of ofloxacin loaded ophthalmic nano structured lipid carriers modified with chitosan oligosaccharide lactate for the treatment of bacterial keratitis. Eur J Pharm Sci. 2014;63:204-15.

67. Jain A, Hurkat P, Jain SK. Development of liposomes using formulation by design: basics to recent advances. Chem Phys Lipids. 2019;224:104764.

68. Jain A, Jain SK. In vitro release kinetics model fitting of liposomes: an insight. Chem Phys Lipids. 2016;201:28-40.

69. Aggarwal D, Kaur IP. Improved pharmacodynamics of timolol maleate from a mucoadhesive niosomal ophthalmic drug delivery system. Int J Pharm. 2005;290(1-2):155-9.

70. Balaguer MP, Fajardo P, Gartner H, Gomez-Estaca J, Gavara $\mathrm{R}$, Almenar E, et al. Functional properties and antifungal activity of films based on gliadins containing cinnamaldehyde and natamycin. Int J Food Microbiol. 2014;173:62-71.

71. Balguri SP, Adelli GR, Janga KY, Bhagav P, Majumdar S. Ocular disposition of ciprofloxacin from topical, PEGylated nanostructured lipid carriers: effect of molecular weight and density of poly (ethylene) glycol. Int J Pharm. 2017;529(1-2):32-43.

Publisher's Note Springer Nature remains neutral with regard to jurisdictional claims in published maps and institutional affiliations. 